\title{
Comendo meu caderno de notas \\ (por uma didática antropófaga do ensino-aprendizado da filosofia)
}

Filipe Ceppas

FE-PPGF UFRJ

O que seria uma aula antropófaga de filosofia, uma sala de aula antropófaga, um trabalho de leitura antropófaga do texto filosófico? (ou, ainda, o que seria uma leitura antropófoga-filosófica de um texto dito "não filosófico"? O que torna filosófico um texto, desde o ponto de vista da Antropofagia?) Se a Antropofagia é um de nossos principais movimentos culturais, literários e filosóficos, por que não pensá-la como um horizonte a partir do qual nossa intervenção pedagógico-filosófica pode chegar a fazer sentido na escola? A Antropofagia trabalha a questão da cultura brasileira como uma cena, cena de cinema: o bispo Sardinha devorado pelos bravos caetés. Predominantemente literária, a construção textual oswaldiana é cinematográfica e essa sua literatura cinematográfica, filosofia.

Subversão da (compreensão da) linguagem. Muito antes do pós-estruturalismo, Oswald "desconstruiu" (literária e teoricamente) os reinos da palavra e da imagem, as regras de separação entre elas, através da materialidade da linguagem, da iconicidade, da colagem, da parataxe, da fragmentação. A rejeição de um centro legitimador da cultura, na literatura oswaldiana, é rejeição de centro nos discursos e na própria linguagem. A antropofagia aproxima-se do pós-moderno ao ensaiar a falência das metanarrativas (o que lembra a blague de Lyotard: "o pós-moderno é condição do moderno". O pós-moderno pode ser entendido como o gesto vanguardista de ruptura com as hierarquias e centros de legitimação, sem o “ismo", sem o "programa” modernista). Rejeição de um centro

1 Jean-François Lyotard, Le Postmoderne expliqué aux enfants, Paris: Galilée, 2005. 


\section{dasQuestões, n.2, fev./maio 2015}

legitimador da cultura, segundo Oswald, em seus textos de 1928: o modernismo supera arcaísmos, mas precisa logo ser superado - quer superar seus limites, como o de ser mero movimento contestatório e, ao mesmo tempo, não quer ser reconhecido como mero substituto da antiga "cultura oficial". Oswald afirmava, na esteira de Baudelaire, que seu modernismo é "clássico", suas obras são o trabalho vigoroso e rigoroso que vem após a "blague”, ou dentro dela. Uma blague grávida de consequências. O que vem depois, junto, juntinho: ingenuidade construtiva, o sarampão marxista, uma cultura relacional: a floresta e a escola. Rejeição de centro na própria linguagem: o significado não comanda o jogo, nem na literatura nem no discurso sobre ela. A blague é séria, toda seriedade deve ser desmascarada. Desconstrução avant la lettre, após a letra, na letra e “de letra”.

\footnotetext{
“58. NOVA-LOMBRADIA

Molhei sêcas pestanas para o rincão corcunda que vira nascer meu pai.

A ponta vermelha da gare de Aradópolis era numa fita de coqueiros.

Fordes quilometravam açafrões de ocaso.” 2
}

Justaposição, simultaneismo, parataxe, metonímia. Como analisa Fernando Gerheim: "O resultado é que a característica de não ter centro e o recurso à metonímia retiram as frases de um campo de profundidade e perspectiva, no qual o sentido penetrasse comodamente. É como se, rechaçado, ele ficasse pulsando na sua superfície. Num paralelo com as artes plásticas, poderíamos dizer que não há distinção entre figura e fundo. $\mathrm{O}$ significado desliza pela superfície da frase sem penetrá-la, em parte como consequência do recurso à metonímia, que atua por contigüidade, descrevendo as coisas por suas qualidades concretas. As palavras são, em vez de símbolos, ícones. E a alteração das funções gramaticais desconecta as partes da frase, fragmentando-as em vez de fazê-las fluir". ${ }^{3}$

2 Minicapítulo de Memórias sentimentais de João Miramar.

3 GERHEIM, Fernando. "Oswald de Andrade: de capa a colofão", in Escrita, revista de pós-graduação em Letras da PUC-Rio, Rio de Janeiro, n⿳⺈, jan'/jun 99, p.37. 


\section{dasQuestões, n.2, fev./maio 2015}

Parentesco de Oswald com Mallarmé, Joyce, Beckett, etc. Fazer o sentido pulsar na superfície. Partindo das relações entre linguagens oral, escrita e imagética, Oswald opõe uma "composição cinematográfica do pensamento" à tese de um "sentido transcendente" do texto. Segundo esta tese, apesar do texto poder ser aceito como polissêmico, sua leitura pressupõe sempre a busca da explicação "a mais correta". Enquanto cena, o texto se presta antes ao saborear e à digestão, como já o tinha anunciado Nietzsche.

O jovem desconfia da promessa do lucro que ele pode ter ao aceitar a sublimação, isto é, ao aceitar, enfim, dedicar-se aos estudos através do "maçante e difícil" exercício da leitura e da escrita. E um dos nossos grandes erros é pensar que ele faz isso apenas porque está perdido numa sociedade consumista, regida pela força das imagens, da indústria cultural e de uma subcultura popular. Ele faz isso, dentre outras coisas, porque nós mesmos reduzimos a escrita a um mero suporte, a um "suplemento", diria Derrida, de um significado transcendente, quase sempre localizado em uma região bem distante no espaço e no tempo, "desconectado da realidade do estudante", como se costuma dizer (ou sem se colocar num verdadeiro enfrentamento com ela, sem guerrear de igual para igual, diríamos nós).

Mais do que isso, é a própria oposição entre escrita e oralidade que parece problemática. Nossa cultura é fonologocêntrica e grafocêntrica. Concebemos a escrita como um suporte indispensável da cultura e mecanismo de distinção e controle, mas o essencial sempre se encontra alhures: o significado é o lugar da essência, e entre a leitura e esse significado, o desvelamento dessa essência, nós exigimos um representante legítimo, que garanta a interpretação correta, quando não nos colocamos nós mesmos, os professores, no lugar de seus guardiões.

Formação, na tradição filosófica do Ocidente, tem a ver com uma certa ventania. Na tradição alemã da Bildung, a formação cultural do indivíduo estará fortemente marcada pela imagem romântica da tempestade, símbolo da capacidade humana de se reconhecer, através do sentimento do sublime, como destinação supra-sensível e grandiosa da 


\section{dasQuestões, n.2, fev./maio 2015}

natureza. A filosofia se reconhece como ápice desse reconhecimento, como "autoconsciência viva do Espírito" (Fichte), a autoconsciência desse sopro que é o pensamento. A formação é esse espírito, esse "sopro", essa ventania em ação, que deve acontecer em alguma medida na vida de cada um de nós. É vertiginoso pensar na experiência desse autorreconhecimento perante a grandiosidade do "Novo Mundo". Nós, que o habitamos, não podemos deixar de fazê-lo. Como disse Blaise Cendrars, o Brasil “...é demasiado grandioso. Procura-se o homem. Ele aí não está, e isto chateia”.

O sentimento grandioso do sublime causa um tipo de ajuizamento que Kant chama de reflexionante. "O juízo reflexionante supõe a capacidade de sintetizar dados fortuitos sem o auxílio de qualquer regra de encadeamento estabelecida previamente." 5 Pensar a pergunta por uma "educação antropófaga" sob o prisma do juízo reflexionante, sem o auxílio de uma regra dada previamente, sob o prisma desse sentimento do grandioso que é a sua causa. As imagens dessa grandiosidade são conhecidas: terra de pecado, terra sem pecado, paraíso edêmico, Eldorado, etc. ${ }^{6}$ Segundo Gadavo, uma terra sem 1 , nem f, nem r (sem lei, nem fé, nem rei). Mundo novo, mundo jovem, "país do futuro”, a imagem mesma da juventude. Qual educação, qual formação para ele? Como diz, ainda, Lyotard, acerca de seus próprios anos de formação: “...a intriga não é jamais trivial se a vivemos sob o apelo da lei”. Qual lei devemos adotar para pensar a educação e a formação cultural nesse caldeirão pós-colonial brasileiro?

O interesse, a curiosidade, a alegria, o aprender, a solidariedade, a conscientização, a libertação, o amor, a emancipação, muitos são os valores recorrentemente elencados para ajudar a compor uma lei sobre a qual a educação deveria se pensar. Comecemos reconhecendo uma certa impotência, senão desses valores e dessas pedagogias, mas da escolarização de modo geral:

4 Le Brésil. Des hommes sont venus, Paris: Gallimard, 2010.

5 Jean-François Lyotard, Pérégrinations, Paris: Galilée, p.26.

6 Ver Sérgio Buarque de Holanda, Visões do Paraíso, São Paulo: Brasiliense/Folha de São Paulo, 200. 
...na maioria dos nossos países [da América do Sul] há grandes massas ainda fora do alcance da literatura erudita, mergulhando numa etapa folclórica de comunicação oral. Quando alfabetizadas e absorvidas pelo processo de urbanização, passam para o domínio do rádio, da televisão, da história em quadrinhos, constituindo a base de uma cultura de massa. Daí a alfabetização não aumentar proporcionalmente o número de leitores da literatura, como a concebemos aqui; mas atirar os alfabetizados, junto com os analfabetos, diretamente da fase folclórica para essa espécie de folclore urbano que é a cultura massificada. ${ }^{7}$

Seria possível dizer (conjuntamente com algumas perspectivas teóricas ufanistas passadas) que há, nessa suposta resistência à “cultura letrada” entre nós, algo de libertador, prenhe de novos movimentos de formação que passam antes pelo sensível, ou por uma outra "lógica" alternativa à autoconsciência viva do Espírito da tradição ocidental? E talvez nem tanto outra "lógica” (um outro lógos, um outro discurso), mas uma outra forma com a qual o Espírito, esse sopro do pensamento, torna-se autoconsciente. Não uma recusa do domínio do discurso (da cultura letrada), mas quem sabe uma outra forma de usá-lo e de valorá-lo.

Para Platão, captar a "forma" das coisas, a idéia, seria a tarefa mais elevada da alma, da psyché, esse sopro do pensamento que, curiosamente, seria o próprio do ser humano. Por outro lado, a metáfora mais fundamental do conhecimento, da captação da idéia, é visual: o sol platônico como idéia da idéia, iluminação da alma e imagens correlatas. A alma vê, mas ela mesma não se vê. Sendo um sopro, um vento, ela é antes um fenômeno tátil, háptico (e, deveríamos acrescentar, também, talvez: térmico).

\title{
Rumo a uma “barbárie positiva”?
}

\begin{abstract}
Abandonamos uma depois da outra todas as peças do patrimônio humano, tivemos que empenhá-las muitas vezes a um centésimo do seu valor para recebermos em troca a moeda miúda do «atual». A crise econômica está diante da porta, atrás dela está uma sombra. (...) Em seus edifícios, quadros e narrativas a humanidade se prepara, se necessário, para sobreviver à cultura. E o que é mais importante: ela o faz rindo. Talvez esse riso tenha aqui e ali um som bárbaro. Perfeito. No meio tempo, possa o indivíduo dar um pouco de humanidade àquela massa, que um dia talvez retribua com juros e com os juros dos juros. ${ }^{8}$
\end{abstract}

7 Cândido, A educação pela noite, São Paulo: Ática, 1989, pp.144-145.

8 Walter Benjamin, "Experiência e pobreza", in Obras escolhidas. Magia e técnica, arte e política, São Paulo: Brasiliense, p.119. 


\section{dasQuestões, n.2, fev./maio 2015}

Mas uma prática de leitura antropófoga-filosófica poderia ser algo talvez menos messiânico; poderia ser algo até mesmo banal: exercícios de leitura de textos filosóficos e não filosóficos (“clássicos" ou não) que não excluem aspectos de um "método estrutural” (suas explicações, a busca de coerência interna do pensamento de um autor), mas privilegiam radicalmente outros, como a colagem, a associação livre, a simultaneidade. O que está em questão, aqui, é a própria idéia do que seja o pensamento que se exercita em nome da filosofia. No Ensino Médio, é fundamental o contato emocional, físico, com as questões e sua expressão-apropriação. Não há qualquer sentido em esperar dos jovens seja que "competência" for que possamos associar à filosofia, tal como nós eventualmente a praticamos na academia. Contato, contágio, encenação, dramatização: é somente sob essas condições que, posteriormente, uma "competência" qualquer pode chegar a ter sentido. Por outro lado, esse exercício nos aproxima daquilo que poderia ser, também para nós, "acadêmicos", a filosofia: um modo de vida.

Pode-se ilustrar essa questão com o exercício de leitura/escrita dos "cadernos de notas" (hypomnémata) analisados por Foucault no texto "A escrita de si" e em $A$ Hermenêutica do sujeito. ${ }^{9}$ Os cadernos de notas, tal como utilizados na antiguidade, têm diversas características. Eles serviam como exercícios que inscreviam a verdade na alma, resumiam leituras e pensamentos, serviam também como matéria de diálogo com os outros, etc. Um aspecto importante tem a ver com o fato de que os cadernos não se prestavam a revelar uma verdade sobre si mesmo, ou que deveria ser buscada (como tudo o que, no mundo cristão, estará subordinado à verdade revelada; ou, ainda, aquilo que, no mundo moderno, estaria subordinado à experiência de uma vida, de uma biografia). Eles eram antes o registro de ditos, casos, ponderações que, uma vez escritos, postos lado a lado

9 Aula de 3 de março de 1982, in FOUCAULT, A Hermenêutica do sujeito. São Paulo: Martins Fontes, 20o6, p.433ss; e FOUCAULT, “A escrita de si”, in Ditos e escritos vol. V. Ética, sexualidade, Política. Rio de Janeiro: Forense Universitária, 2004. Devo a atenção à análise foucaultiana dos hypomnémata e sua importância para pensar o ensino-aprendizado escolar da filosofia a Hubert Vincent. 


\section{dasQuestões, n.2, fev./maio 2015}

com outros ditos, casos, ponderações, devem estar disponíveis, devem ser facilmente consultados ou lembrados perante situações que os solicitem. Trata-se, além do mais, de uma certa economia do ler e do escrever: nem ler demais, nem escrever demais. Frases curtas, casos resumidos.

A "meditação" proposta pelo caderno de notas começa por ser uma apropriação. Como diz Foucault, dado um texto, não se trata de perguntar sobre o que ele quer dizer, "ao contrário, trata-se de apropriar-se [de um pensamento], de dele persuadir-se tão profundamente que, por um lado, acreditamos que ele seja tão verdadeiro e, por outro, podemos constantemente redizê-lo, redizê-lo tão logo a necessidade se imponha ou a ocasião se apresente" (A Hermenêutica do sujeito, op.cit p.429). Encenação que se aprofunda com um segundo aspecto: "meditatio (...) consiste em fazer uma espécie de experiência, experiência de identificação. Quero com isso dizer que na meditatio trata-se não tanto de pensar a própria coisa, mas de exercitar-se na coisa que se pensa" (idem). Antropofagicamente, interessa-nos a dimensão corporal daquele apropriar-se, daquele dispor do que se leu ou do que se escreveu, assim como desse estar naquilo que se pensa. "O exercício de leitura não era fácil: não se tratava de ler simplesmente com os olhos. Para se chegar a destacar as palavras como convinha, era-se obrigado a pronunciá-las, pronunciálas em voz baixa" (p.432). ${ }^{10}$ Para ilustrar a "unificação de fragmentos heterogêneos pela sua subjetivação no exercício da escrita pessoal”, Foucault menciona o uso que Sêneca faz da metáfora da digestão: "Digiramos a matéria: caso contrário, ela entrará em nossa memória, não em nossa inteligência [in memoriam non in ingenium]." ${ }^{\text {11 }}$ E Foucault complementa: "O papel da escrita [nos hypomnémata] é constituir, com tudo o que a leitura constituiu, um corpo (quicquid lectione collectum est, stillus redigat in corpus). E é preciso compreender

10 Hoje, uma regra burguesa da leitura é o silêncio, a leitura silenciosa. Aqueles que murmuram enquanto lêem são vistos e estigmatizados como pessoas que tem dificuldade de ler. Também em seus primórdios, as salas de cinema eram barulhentas. Hoje, "novos bárbaros" as invadem com ruídos de todo tipo. Essa aproximação talvez possa ser melhor pensada a partir da tese benjaminiana da "babárie positiva”.

11 Sêneca, apud, Foucault, "A escrita de si”, op.cit, p.152. 


\section{dasQuestões, n.2, fev./maio 2015}

esse corpo não como um corpo de doutrina, mas sim — segundo a metáfora da digestão tantas vezes evocada - como o próprio corpo daquele que, transcrevendo suas leituras, delas se apropriou e fez sua a verdade dela: a escrita transforma a coisa vista ou ouvida 'em forças e em sangue' (in vires, in sanguinem).” (idem, p.152).

Por mais articulado que seja, o pensamento dos adolescentes parece estar sempre fortemente marcado pela heteronomia, pela pressão do olhar alheio. A cada instante, parece que a verdade de seu ser será posta em jogo pelo olhar alheio. Essa heteronomia se dá antes por embate e negação do que pela incorporação. Desconfiança, enfrentamento, ou pura indiferença são comportamentos comuns que a maioria dos jovens desenvolve como reação ao olhar adulto, o que funciona muitas vezes como um obstáculo a mais no aprendizado escolar. As "matérias escolares" podem, por vezes, aparecer como terreno neutro, mas não a filosofia, naquilo que ela tem de específico. Se "a filosofia" pretende ser mais do que matéria escolar; ${ }^{12}$ se exercitar o pensamento pretende ser "filosófico" e "significativo para a vida" (o que implica, desde uma perspectiva antropófaga, uma certa deglutição do outro), o questionamento dessa relação, desse olhar, dessas reações, torna-se condição mesma para um gesto pedagógico possível; “a filosofia” deve ser, antes de mais nada, convite para mastigar as causas desses comportamentos; digestão: atenção para com as armadilhas dos mecanismos que fazem com que certas palavras, certos discursos, certos gestos, funcionem sempre como o que separa, hierarquiza e oprime. Assim, a filosofia na sala de aula, de um ponto de vista antropófago, não deve ser simples acesso a conhecimentos (hipóteses, problemas, questões, doutrinas) mais ou menos "elevados", mais ou menos "importantes" (nada mais inútil do que querer convencer o/a adolescente da importância de um tema, de um problema); nem deve ser o confronto entre estes conhecimentos e o "senso comum". Este acesso e esse confronto seriam, no máximo, uma

12 Do contrário, a aproximação à antropofagia não me parece fazer sentido. Falar em antropofagia é sempre, necessariamente, o desafio de nos pensarmos herdeiros de uma tradição indígena e guerreira, com suas aproximações e distanciamentos frente às esquisitices do homem branco (filosofia incluída). 


\section{dasQuestões, n.2, fev./maio 2015}

consequência eventual, um momento posterior e dependente do processo que Foucault, seguindo os antigos, chama "tornar-se um sujeito capaz de buscar a verdade" (ou capaz de, em a encontrando, saboreá-la, devorá-la).

Nada de metáfora aqui. A antropofagia é senha de uma relação social-cultural conflituosa (a vingança entre tribos: a relação de inimizade fundadora da cultura, na interpretação de Eduardo Viveiros de Castro), ${ }^{13}$ em que estão envolvidas, de forma relacionada, percepções temporais e identitárias radicalmente diferentes daquelas vigentes nas categorias-coordenadas ocidentais acerca do tempo, do eu, do outro, etc. Uma aula antropófaga de filosofia é, também, uma aproximação a esse conflito e a todos os enormes desafios que podem ser ilustrados pela oposição, aparentemente simplista, dos índios que preservam a floresta intacta contra os habitantes das cidades, que a destróem. Uma aula de filosofia antropófaga deveria ser, também, aprendizado de permacultura. Ver a cidade como selva, transformar a cidade em selva. Salvá-la.

Como mostra a antropologia, e sobretudo o trabalho seminal de Eduardo Viveiros de Castro, desde o ponto de vista da antropofagia (isto é, desde um ponto de vista que leva à sério nossas heranças indígenas, guerreiras, o nosso "pensar selvagem"), os esquemas conceituais e lingüísticos dos indígenas compõem uma intricada rede que desafia radicalmente os esquemas conceituais, científicos e culturais que associamos, meio que genericamente, à "metafísica ocidental”. Uma filosofia antropófaga, uma filosofia a golpes de tacape seria, em primeiro lugar, um desafio para pensar "no desvio rotativo" em que estamos a partir de uma língua "natural e neológica”:

Somos concretistas. As idéias tomam conta, reagem, queimam gente nas praças públicas. Suprimamos as idéias e as outras paralisias. Pelos roteiros. Acreditar nos sinais, acreditar nos instrumentos e nas estrelas (Manifesto antropófago)

13 Eduardo Viveiros de Castro, A Inconstância da Alma Selvagem, São Paulo: Cosacnaify, 2002. 


\section{dasQuestões, n.2, fev./maio 2015}

Se podemos recusar, na esteira de Nietzsche, a identificação do pensamento com qualquer tipo de "egipcismo", ciência de mumificação e decifração/tradução de hieróglifos em ideias, podemos assumir, também, que a mestiçagem é uma condição em que linguagem e pensamento se projetam em forma hieroglífica (cinematográfica, [pós]modernista). Roteiros! A linguagem é "sem fundo". Pensamento de pura superfície, na qual ou a partir da qual algo pode acontecer: um sintoma, um encontro, uma lembrança, uma equação, uma surpresa ("contra a cópia, pela invenção e pela surpresa" - Manifesto da Poesia Pau-Brasil). Nisto também Oswald aproxima-se de Nietzsche: pensar hieroglificamente, a linguagem fora do esquema causal, é exercitar a crítica radical ao preconceito mais arraigado da metafísica ocidental: que as pessoas, porque dizem "Eu", fazem pulular essências fixas e causas e todo um reino de propriedades (e todo o reino da propriedade).

Segundo seu aparecimento, a linguagem pertence ao tempo da forma mais rudimentar de psicologia. Inserimo-nos em um fetichismo grosseiro quando trazemos à consciência os pressupostos fundamentais da linguagem metafísica: ou, em alemão, da razão. Esse fetichismo vê por toda parte agentes e ações; ele crê na vontade enquanto causa em geral; ele crê no "Eu", no Eu enquanto Ser, no Eu enquanto Substância, e projeta essa crença no Eu-substância para todas as coisas. - Só a partir daí a consciência cria então o conceito "coisa"... Por toda parte, o Ser é introduzido através do pensamento, imputado como causa. Somente a partir da concepção do "Eu" segue, enquanto derivado, o conceito "Ser"..."

Uma filosofia antropófaga a golpes de tacape afirma, antes, a "transformação permanente do Tabu [o proibido, o ateismo, o matriarcado, a felicidade anárquica] em totem" (“Já tínhamos o comunismo. Já tínhamos a língua surrealista”). A filosofia antropófaga enquanto filosofia crítica é a busca por um pensamento que esteja à altura do comunismo e da alegria, enquanto parte de nossas heranças indígenas. Valorização do ócio contra o negócio, a utopia do matriarcado, o índio tecnizado. Uma aula de filosofia antropófaga é, por fim, enfrentamento radical contra o capitalismo, contra o patriarcado e contra os valores burgueses do que seja ser civilizado.

14 Crepúsculo dos ídolos ou como se filosofa com o martelo. Trad. Paulo César de Souza. São Paulo: Companhia das Letras, 2006. 
Como nosso olhar para a cultura brasileira informa aquilo que acreditamos possível, desejável, importante de ser trabalhado em sala de aula em nome da filosofia? Como montamos nós mesmos nossos cadernos de notas sobre nossa tarefa nas escolas? Onde, nesses cadernos, encontramos Oswald, Sérgio Buarque, Gilberto Freyre, Paulo Freire, Viveiros de Castro e tantos outros e outras pensadoras da cultura brasileira? 